\title{
Influence of exclusive breast feeding on occurrence, severity and recurrence of acute lower respiratory infections in preschool children
}

\author{
S N Pathirage ${ }^{1}$, S Pathigoda ${ }^{1}$, R Peiris ${ }^{1}$, S Sri Ranganathan ${ }^{2}$ \\ Sri Lanka Journal of Child Health, 2009: 38: 21-24
}

(Key words: Breast feeding, acute lower respiratory tract infections, case-control study)

\begin{abstract}
Objective: To determine the association between acute lower respiratory infections (ALRI) and exclusive breast feeding practices in children younger than five years of age
\end{abstract}

Design: Case control study

Setting: Lady Ridgeway Hospital for Children, Colombo.

Method: Breast feeding practices in children younger than five years of age admitted with ALRI were compared with that of age and gender matched controls. An interviewer administered structured pretested questionnaire was used to collect the data.

Results: One hundred and four cases and controls were studied; $53 \%$ of cases were exclusively breast fed for four or more months compared to $68 \%$ of controls (odds-ratio 2). Of the 14 cases with severe ALRI, 14\% were exclusively breast fed for four or more months compared to $56 \%$ in non severe ALRI cases (odds-ratio 7.5). Proportion of children exclusively breast fed for four or more months was significantly lower $(p<0.001)$ in cases who had previous hospital admissions for ALRI (31\% against $62 \%)$.

Conclusions: This study provides further evidence that exclusive breast feeding has protective effect on occurrence, severity and recurrence of ALRI in young children.

${ }^{1}$ Medical student, Faculty of Medicine, University of Colombo, ${ }^{2}$ Senior Lecturer in Pharmacology and Consultant Paediatrician, Faculty of Medicine, University of Colombo.

(Received on 21 April, 2008. Accepted on 24 April 2008)

\section{Introduction}

Acute lower respiratory infection (ALRI) is a major cause of morbidity and mortality in children under the age of five years. Each year, more than 10 million children worldwide die before their first birthday, and more than $97 \%$ of these deaths occur in developing countries $^{1,2}$. Acute respiratory infection, mainly pneumonia contributes to about $20 \%$ of these deaths in children under the age of five years ${ }^{3}$.

Breast feeding reduces the risk of respiratory infections in infants. A meta-analysis published in 2003 which looked at breast feeding and the risk of hospitalization for respiratory disease in infancy concluded that exclusive breast feeding for 4 or more months appears to diminish the risk of respiratory hospitalization in infancy to one third or less the risk observed for formula-fed infants in even developed nations with high standards of medical care and sanitation $^{4}$.

Accumulating evidence of the benefits of exclusive breast feeding led to a recommendation by the World Health Organization that it be done for the first six months instead of the initial recommendation of four months. Re-analysis of studies in Brazil and Bangladesh has found breastfed infants in the first six months of life who were given additional foods had a twofold to threefold higher mortality from diarrhoea and pneumonia in comparison with infants who were exclusively breastfed ${ }^{5,6}$.

As a preventive measure against respiratory infections, promoting breast feeding is more affordable than medical and sanitary interventions in developing countries like Sri Lanka. Survey done in 1993 reported that even though the general breast feeding rate is over $95 \%$ immediately after birth in Sri Lanka, the exclusive breast feeding rate in the first 4-6 months of life is around 10-15\% ${ }^{7}$. A study done in Lady Ridgeway Hospital, Colombo (1997) reported that significant numbers of babies who were not breast fed or breast fed for less than three months 
developed the first diarrhoeal or respiratory illnesses during the first three months following introduction of other foods ${ }^{8}$.

Best breast feeding practice includes time of first feed, breast feeding pattern, duration of exclusive breast feeding, total duration of breast feeding, introduction of formula milk and weaning. Adhering to the evidence based recommendation for each of these components will maximally protect the infants from ALRI and diarrhoeal episodes. Hence it will be useful to describe the association between the frequency and severity of ALRI and these different components of breast feeding.

\section{Objective}

To determine the association between ALRI and exclusive breast feeding practices in hospitalized children younger than five years of age.

\section{Method}

The study was carried out at the Lady Ridgeway Hospital (LRH) for Children, Colombo. It was a case control study where children younger than five years of age admitted to LRH for ALRI were compared with age and gender matched controls for breast feeding practice. The study period was one month (October-November 2006). The study population comprised one hundred and four cases and a similar number of age and gender matched controls.

Cases were defined as children aged 0-5 years with acute lower respiratory infection. ALRI was defined as presence of cough and fever with one or more of the following features: increased respiratory rate, chest indrawing, crepitations or rhonchi. Controls were defined as age and gender matched children admitted to LRH during the study period for other problems not related to respiratory or cardiac problems.

Children with the following conditions were excluded from the study: (i) children with a history of preterm birth, (ii) children diagnosed to have congenital heart diseases, lung diseases and upper gastrointestinal abnormalities, (iii) children with chromosomal abnormalities, (iv) children known to be immuno- compromised or on immuno-suppressive therapy, (v) children diagnosed to have bronchial asthma and (vi) children diagnosed to have pulmonary TB.

Modified WHO criteria were adopted in assessing the severity of ALRI'. History of previous hospital admission/s for ALRI was used as an indicator to determine recurrence of ALRI.

A pilot study was carried out in LRH in 12 cases before beginning the study proper and required amendments were done.

An interviewer administered structured pre-tested questionnaire was used to collect data from both cases and controls. Investigators visited the medical wards daily and identified the cases based on clinical history, examination findings at the time of visit, records in bed head tickets and discussion with the ward doctors. Age and gender matched controls were selected mainly from surgical wards. Required information was obtained by interviewing the mothers, going through the bed head tickets and examining the child.

Cases were compared with controls for time of first feed, feeding pattern during the first four months, duration of exclusive breast feeding and total duration of breast feeding. SPSS software (14th version) was used for the analysis. Further analysis was done by comparing the mild and severe ALRI cases with those of very severe cases for these different components of breast feeding practice.

Ethical clearance was obtained from Institutional (LRH) Ethical Review Committee. Permission for data collection was obtained from the Director of $\mathrm{LRH}$, and respective Consultants. Informed verbal consent was obtained from mothers before interviewing them. Refusal to participate was honoured.

\section{Results}

One hundred and four cases and 104 age and gender matched controls were enrolled; mean age of cases and controls were respectively, $20.4(\mathrm{SD}=14.9)$ and 19.9 (S.D=13.7) months. Male to female ratio in both cases and controls was 1.3: 1 (Table 1) 
Table 1

Age and gender distribution of cases and controls

\begin{tabular}{lcccccc}
\hline \multirow{2}{*}{ Age group } & \multicolumn{3}{c}{ Cases } & \multicolumn{1}{c}{ Controls } \\
\cline { 2 - 6 } & Females & Males & Total & Females & Males & Total \\
\hline 31-180 days & 05 & 11 & 16 & 05 & 11 & 16 \\
181-365 days & 11 & 08 & 19 & 30 & 39 & 19 \\
> 1 year & 30 & 39 & 69 & 46 & 58 & 69 \\
Total & 46 & 58 & 104 & & 104 \\
\hline
\end{tabular}

Eighty six percent $(95 \% \mathrm{CI}=77,91)$ of cases and $85 \%(95 \% \mathrm{CI}=76,90)$ of controls have received the first feed within one hour of birth. No statistically significant relationship was observed in the time of first feed between cases and controls $(p>0.05)$.

Fifty five $(53 \%, 95 \% \quad \mathrm{CI}=43,63)$ cases were exclusively breast fed for four or more months compared to $71(68 \%, 95 \% \quad \mathrm{CI}=58,76)$ controls (odds-ratio 2).

Formula feeds were introduced in first four months in $18 \%(95 \% \mathrm{CI}=12,26)$ of cases, compared to $5 \%$ $(95 \%$ CI $=2,11)$ of controls and almost equal proportions of cases and controls were predominantly breast fed (child is given water or water based drinks such as juice in addition to breast milk but not formula milk or food based drinks).

Twenty four percent $(95 \% \mathrm{CI}=17,33)$ of cases were breast fed for less than eight months compared to $8 \%$ $(95 \% \mathrm{CI}=5,15)$ of controls. Cases were more than the controls in the group who received breast milk for a period of 4-8 months whereas controls were predominant in other groups (duration of breast feeding 8-12, 12-18 and >18 months) (Figure 1).

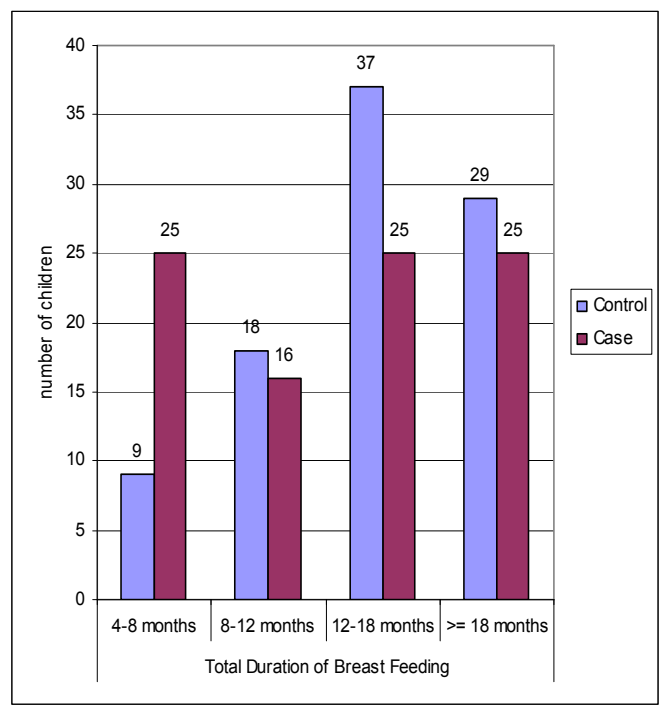

Figure 1 Duration of total breast feeding in cases and controls
There were 14 cases $(13 \%, 95 \% \mathrm{CI}=8,21)$ with severe ALRI. Of these 14 cases with severe ALRI, $14 \%(95 \% \mathrm{CI}=8,22)$ were exclusively breast fed for four or more months compared to $56 \%(95 \% \mathrm{CI}=46$, 65 ) of non severe ALRI cases (odds-ratio 7.5).

There were 39 cases $(37.5 \%, 95 \% \mathrm{CI}=29,47)$ with a history of previous hospital admission for ALRI. Proportion of children exclusively breast fed for four or more months was significantly $(\mathrm{p}<0.001)$ lower in cases who had previous hospital admissions for ALRI $(31 \%, 95 \% \mathrm{CI}=23,41)$ compared to that of the cases who did not have $(62 \%, 95 \% \mathrm{CI}=52,71)$.

\section{Discussion}

In our study population, $98.6 \%$ of children were breast fed. This included exclusive breast feeding, predominant breast feeding, breast feeding followed by formula milk or breast feeding combined with formula milk. In 1993, the breast feeding rate immediately after birth in Sri Lanka was $95 \%{ }^{7}$. We found a similar value.

Though WHO recommends six months of exclusive breast feeding, only $5.3 \%$ of the whole study sample (inclusive of cases and controls) were exclusively breast fed for six months, and 60.6.\% were for four months. This estimates that about $55 \%$ of mothers in our study population stopped exclusive breast feeding between 4 and 6 months.

Our results are in agreement with other studies ${ }^{4,5,6,8}$ showing a significant difference in the duration of exclusive breast feeding in the two groups. This study also provides evidence albeit in small numbers that breast feeding influences severity and recurrence of ALRI. Though we wanted to compare the cases and controls for proportion of babies exclusively breast fed for six months or more, we finally analysed the proportion of babies exclusively breast fed for four months or more. This is because there were altogether only 11 babies who were breast fed more than six months in the 208 cases and controls. 
Parents need to be educated about the advantages of breast feeding and that breast feeding is a cost effective mode of primary prevention of ALRI.

\section{Conclusion}

There was a significant association between acute lower respiratory infections and exclusive breast feeding practice in children younger than five years of age

\section{Acknowledgements}

We thank the Head and Staff of Department of Community Medicine, Faculty of Medicine, Colombo for organizing this research programme. We thank Director/LRH, Dr BJC Perera and Consultants of Lady Ridgeway Hospital for their advice and permission to recruit the study population and collect data. We also acknowledge all mothers and children who participated in the study.

\section{References}

1. Bellamy C. The state of the world's children 2003. Geneva: United Nations Children's Fund; 2002.

2. Ahmad OB, Lopez AD, Inoue M. The decline child mortality: a reappraisal. Bulletin of the World Health Organization 2000; 78: 1175-91.

3. Williams BG, Gouws E, Boschi-Pinto C, Bryce J, Dye C. Estimates of world-wide distribution of child deaths from acute respiratory infections. Lancet Infectious Diseases 2002; 2: 25-32.

4. Bachrach VRG, Schwarz E, Bachrach LR. Breast feeding and the risk of hospitalization for respiratory disease in infancy. Archives of Paediatrics \& Adolescent Medicine 2003; 157: 237-48.

5. Victora CG, Vaughan JP, Lombardi C, Fuchs SMC, Gigante LP, Smith PG, et al. Evidence for protection by breast-feeding against infant death from infectious diseases in Brazil. Lancet 1987; ii: 319-21.

6. Arifeen S, Black RF, Antelman G, Baqui A, Caulfield L, Becker S. Exclusive breast feeding reduces acute respiratory disease and diarrhea deaths among infants in Dhaka slums. Paediatrics 2001; 108:E67.

7. Department of Census and statistics. Demographic and health survey. Colombo: Department of Census and Statistics, Colombo; 1993.

8. Perera BJC, Ganesan S, Jayarasa J, Ranaweera S. The impact of breast feeding practices on respiratory and diarrhoeal disease in infancy: a study from Sri Lanka. Journal of Tropical Paediatrics 1999; 45:115-8.

9. World Health Organization. Pocket book of hospital care for children. Geneva: World Health Organization; 2005. 